\title{
ANTIBIOTIC SUSCEPTIBILITY OF SALMONELLA SPP.: A COMPARISON OF TWO SURVEYS WITH A 5 YEARS INTERVAL
}

\author{
Gordana Mijovic ${ }^{1}$, Bogdanka Andric ${ }^{2}$, Dragica Terzic ${ }^{2}$, Milena Lopicic ${ }^{1}$, Brankica \\ Dupanovic ${ }^{2}$ \\ ${ }^{1}$ Institute of public health, Podgorica. \\ ${ }^{2}$ Clinic for infectious diseases, Clinical center of Montenegro, Podgorica, \\ Montenegro
}

\section{SUMMARY}

Salmonella infections are one of the major global public health problems. During the last decade, antibiotic resistance and multiresistance of Salmonella spp. have increased a great deal, especially in developing countries with an increased and indiscriminate use of antibiotics in the treatment of humans and animals.

This study aims to investigate and compare antimicrobial susceptibility patterns of Salmonella during 2005 and 2010.

A total of 186 Salmonella strain during 2005 and 140 Salmonella strain during 2010 were isolated from stool specimens using standard methods. The isolates were confirmed as Salmonella by using a battery of biochemical reactions. Specific antisera were used for serologic characterization of Salmonella strain. Antimicrobial susceptibility testing was performed by standard disk diffusion method using ampicillin, trimethoprimsulfamethoxasole, ceftriaxon, chloramphenicol, nalidixic acid and ciprofloxacin.

One hundred eighty $(96.8 \%)$ of 186 isolated Salmonella strains in 2005, and $133(95 \%)$ of 140 isolated Salmonella strain in 2010 are recognized as Salmonella Enteritidis. Sensitivity of Salmonella isolates during 2005 and 2010 were $91.9 \%$ and $92.9 \%$ to ampicillin, $95.7 \%$ and $97.1 \%$ to trimethoprim-sulfamethoxasole, $99.5 \%$ and $100 \%$ to chloramphenicol, $99.5 \%$ and $100 \%$ to ciprofloxacin, $98.9 \%$ and $97.1 \%$ to ceftriaxon, $73.1 \%$ and $95.7 \%$ to nalidixic acid, respectively.

Sensitivity of Salmonella isolates to all tested antimicrobial agents except to ceftriaxon was been slightly improved over testing period. Resistance rate to ceftriaxon was higher in 2010 than in 2005, and this fact deserves attention. Significantly increase susceptibility rate to nalidixic acid was observed between the two surveys.

Key words: nontyphoid, salmonella, antibiotic susceptibility

\section{INTRODUCTION}

Diarrheal disease is an important global problem that causes high rates of morbidity and mortality in developing countries. Among the bacteria causing diarrhea, Salmonella continues to be at first place. Over the last two decades the incidence of nontyphoidal Salmonella infections has increased. It is estimated that nontyphoidal Salmonella cause between two hundred million and 1.3 billion cases of intestinal disease including 3 million of death each year worldwide ${ }^{(1)}$. Salmonellosis are the second most commonly reported human zoonoses in spite of a decrease in incidence over the last three years in EU ${ }^{(2)}$.

Recently, specific serovars were linked with certain foods or exposures. For example, outbreaks of Salmonella serovar Enteritidis have been repeatedly associated with raw or undercooked eggs ${ }^{(3)}$ and Salmonella Marina infection has been associated with exposure to reptiles ${ }^{(4)}$.

Infection with nontyphoidal Salmonella usually results in a self-limiting gastroenteritis that does not require antibiotic therapy, but sometimes serious sequellae, including systemic infection and death, may occur (5).

Examining the antibiotic susceptibility patterns of pathogens is important toward tailoring treatment to the ever changing resistance patterns and distribution of pathogenic bacteria.

During the last decade, antibiotic resistance and multiresistance of Salmonella spp. have increased a great deal, especially in developing countries with an increased and indiscriminate use of antibiotics in the treatment of humans and animals ${ }^{(6)}$.

Various Salmonella serovars resistant to conventional antibiotics such as ampicillin, chloramphenicol, trimethoprim-sulfamethoxazole, and other newer antibiotics (quinolones and extended-spectrum cephalosporins) have been reported with increasing frequency in many areas of the world ${ }^{(5)}$.

Among the nontyphoidal Salmonella enterica serovar Typhimurium has been reported to show multidrug 
resistance $^{(7)}$.

This study aims to investigate and compare antimicrobial susceptibility patterns of Salmonella during 2005 and 2010.

\section{MATERIALAND METHOD}

A total of 186 Salmonella strain during 2005 and 140 Salmonella strain during 2010 were isolated from stool specimens using standard methods.

Using sterile swabs, the stool samples were directly inoculated onto plates of SS agar (Himedia, HIMedia Laboratiries Pvt.Ltd. India). The same samples were then plated onto Selenite F broth (BIOTEC, BIOTEC Laboratories Ltd, UK) and incubated as aforestated for enrichment. Agar plates and enrichment broth were incubated aerobically at $37 \mathrm{eC}$ for 20-24 hours. Following the incubation of Selenite $\mathrm{F}$ broth, a loopful was streaked onto SS agar plates and incubated at $37^{\circ} \mathrm{C}$ for $24 \mathrm{~h}$. One to three colonies suspected to be Salmonella (small colorless colonies sometimes with black spot) were selected and characterized biochemically using Kligler Iron Agar (KIA) and Urease tests.

Specific antisera were used for serologic characterization of Salmonella strain. Antimicrobial susceptibility testing was performed by standard disk diffusion method (NCCLS, 1997; 2001) using ampicillin, trimethoprim-sulfamethoxasole, ceftriaxon, chloramphenicol, nalidixic acid and ciprofloxacin (Beckton Dickinson, MD).

\section{RESULTS}

Salmonella Enteritidis was the most common isolated serovar during 2005 and 2010 (96.8\%; 95\%, respectively). Salmonella gr. B with $3.2 \%$ isolation rate was the second most isolated serovar in 2005. Serovars distribution is shown in table 1 .

Table 1. Distribution of Salmonella serovars during 2005 and 2010

\begin{tabular}{|l|l|l|l|l|l|l|}
\hline \multirow{2}{*}{ Salmonella SEROVAR } & \multicolumn{2}{|l|}{ YEAR } & 2010 & \multicolumn{2}{l|}{ TOTAL } \\
\cline { 2 - 6 } & 2005 & No & $\%$ & No & $\%$ \\
\cline { 2 - 6 } & No & $\%$ & 133 & 95 & 313 & 96 \\
\hline Salmonella Enteritidis & 180 & 96.8 & 2.2 & 1.4 & 8 & 2.5 \\
\hline Salmonella gr.B & 6 & 3.2 & 1 & 0.7 & 1 & 0.3 \\
\hline Salmonella Paratyphi B & 0 & 0 & 1 & 0.7 & 1 & 0.3 \\
\hline Salmonella gr. C & 0 & 0 & 1 & 0.7 & 1 & 0.3 \\
\hline Salmonella Infantis & 0 & 0 & 1 & 0.7 & 1 & 0.3 \\
\hline Salmonella Wirchow & 0 & 0 & 1 & 0.7 & 1 & 0.3 \\
\hline Salmonella gr.A & 0 & 0 & 1426 & 326 \\
\hline TOTAL & 186 & 100 & 140 & 100 & & 100 \\
\hline
\end{tabular}

Three strain Salmonella gr. C and one strain Salmonella gr. A were isolated in 2010.

The antibiotic susceptibility of Salmonella isolates is shown in table 2.

Table 2. Antibiotic susceptibility of salmonella isolates

\begin{tabular}{|c|c|c|c|c|c|c|c|c|c|c|c|c|}
\hline \multirow{3}{*}{ ANTIBIOTICS } & \multicolumn{4}{|c|}{2005} & \multicolumn{4}{|c|}{2010} & \multicolumn{4}{|c|}{ Total } \\
\hline & \multicolumn{2}{|c|}{ Sensitive } & \multicolumn{2}{|c|}{ Resistant } & \multicolumn{2}{|c|}{ Sensitive } & \multicolumn{2}{|c|}{ Resistant } & \multicolumn{2}{|c|}{ Sensitive } & \multicolumn{2}{|c|}{ Resistant } \\
\hline & No & $\%$ & No & $\%$ & No & $\%$ & No & $\%$ & No & $\%$ & No & $\%$ \\
\hline Ampicillin & 171 & 91.9 & 15 & 8.1 & 130 & 92.9 & 10 & 7.1 & 301 & 92.3 & 25 & 7.7 \\
\hline Trim/sulfameth. & 178 & 95.7 & 8 & 4.3 & 136 & 97.1 & 4 & 2.9 & 314 & 96.3 & 12 & 3.7 \\
\hline Ceftriaxon & 184 & 98.9 & 2 & 1.1 & 136 & 97.1 & 4 & 2.9 & 320 & 98.2 & 6 & 1.8 \\
\hline Nalidixic acid & 136 & 73.1 & 50 & 26.9 & 134 & 95.7 & 6 & 4.3 & 270 & 82.8 & 56 & 17.2 \\
\hline Ciprofloxacin & 185 & 99.5 & 1 & 0.5 & 140 & 100 & 0 & 0 & 325 & 99.7 & 1 & 0.3 \\
\hline Chloramphenicol & 185 & 99.5 & 1 & 0.5 & 140 & 100 & 0 & 0 & 325 & 99.7 & 1 & 0.3 \\
\hline
\end{tabular}

Thirty-seven percent of Salmonella isolates were resistant to at least one antimicrobial in 2005 , and $10 \%$ in 2010 . It was significant difference $(\mathrm{p}=0.00<0.05)$ (table 3$)$. 
Table 3. Total susceptibility to antimicrobial according to years

\begin{tabular}{|l|l|l|l|l|l|l|}
\hline \multirow{3}{*}{ Susceptibility } & \multicolumn{2}{|l|}{ YEAR } & \multicolumn{2}{l}{ TOTAL } \\
\cline { 2 - 7 } & 2005 & & 2010 & & \multicolumn{2}{|c|}{} \\
\cline { 2 - 7 } & No & $\%$ & No & $\%$ & No & $\%$ \\
\hline Susceptible to all antimicrobial & 118 & 63.4 & 126 & 90 & 244 & 74.8 \\
\hline Resistant to at least one antimicrobia & 68 & 36.6 & 14 & 10 & 82 & 25.2 \\
\hline TOTAL & 186 & 100 & 140 & 100 & 326 & 100 \\
\hline
\end{tabular}

The incidence of multidrug resistance (MDR resistance to three or more antibiotics) in Salmonella strains was $1.6 \%$ in 2005 and $2.1 \%$ in 2010 (table 4).

Table 4. The incidence of multidrug resistance Salmonella strain

\begin{tabular}{|l|l|l|l|}
\hline Year & $\begin{array}{l}\text { No of } \\
\text { isolates }\end{array}$ & $\begin{array}{l}\text { No of MDR } \\
\text { Salmonella }\end{array}$ & $\begin{array}{l}\% \text { of MDR } \\
\text { Salmonella }\end{array}$ \\
\hline 2005 & 186 & 3 & 1.6 \\
\hline 2010 & 140 & 3 & 2.1 \\
\hline TOTAL & 326 & 6 & 1.8 \\
\hline
\end{tabular}

Multiresistant strains of Salmonella were isolated in higher percent in $2010(2.1 \%)$ than in $2005(1.6 \%)$, but the difference was not significant $(\mathrm{p}=0.725>0.05)$. All multiresistant strains were Salmonella Enteritidis.

\section{DISCUSSION}

Over 2500 serovars of $S$. enterica have been identified belonging to six subspecies. S. enterica species are typically orally acquired pathogens which represent more than $99.5 \%$ of the Salmonella strains isolated from humans and other warm-blooded animals ${ }^{(8,9)}$.

In our investigation there was one isolate Salmonella Paratyphi B in 2010. Salmonella gr. B was the second most isolated serovar in 2005, but in 2010 there was greater diversity of isolated serovars than in 2005. Salmonella gr. B and Salmonella gr. C were isolated with the same frequency in 2010. Salmonella Enteritidis has been the most common isolated serovar in both years of survey. Salmonella strains without identified serovars were rarely serovars and laboratory did not have appropriate antisera for its identification.

There is a disturbing general trend in Salmonella serovars being resistant to commonly used antimicrobials. Antimicrobial resistance among human Salmonella isolates is increasing worldwide and is likely due to the widespread use of antimicrobial agents for the empiric treatment of febrile syndromes and as growth enhancers in animal production ${ }^{(10)}$. High rates of resistance to ampicillin, chloramphenicol, tetracycline, and trimethoprimsulfamethoxazole have been reported from many areas of the world ${ }^{(5)}$. Also resistance of Salmonella to newer antibiotics (quinolones and extended spectrum cephalosporins) has been demonstrated in developing as well as developed countries with increasing frequency $(5,11,12,13)$.

Results in our study show that the frequency of Salmonella strains susceptible to all tested antibiotic was significantly higher in 2010 than in 2005 . Our data show that the majority of isolates (90\%) in 2010 were susceptible to all tested antibiotics.

Although the rate of sensitivity to individual antibiotics was higher in 2010 than in 2005, a slight increase of multi-resistant strains was marked in 2010 compared to 2005.

Multidrug-resistant (MDR) strains of Salmonella are now encountered frequently worldwide and the rates of multidrug-resistance have increased considerably in recent years. Even worse, some variants of Salmonella have developed multidrug-resistance as an integral part of the genetic material of the organism, and are therefore likely to retain their drug-resistant genes even when antimicrobial drugs are no longer used, a situation where other resistant strains would typically lose their resistance ${ }^{(14)}$.

Out of all tested antibiotics Salmonella isolates had the lowest level of susceptibility to nalidixic acid in 2005 and ampicillin in 2010. Salmonella isolates had the second lowest level of susceptibility to ampicilin (91.9\%) in 2005 and nalidixic acid $(95.7 \%)$ in 2010 . We detected a significant increasing susceptibility to nalidixic acid in 2010 (95.7\%) compared to 2005 (73.1\%). Nalidixic acid has not been on the registered drug list for several years in Montenegro.

The highest level of susceptibility was detected to chloramphenicol and ciprofloxacin in both years of our investigation.

The investigation of sensitivity of Salmonella Enteritidis strains in Europe in 2006 shows results similar to our once concerning the resistance to ampicillin (8.1\%), chloramphenicol $(0.3 \%)$ and ciprofloxacin $(0.6 \%)$. The rate of resistance to nalidixic acid was higher in 2005 than those in Europe in 2006 (14.8\%) (The Community Summary Report). 


\section{CONCLUSION}

The sensitivity of Salmonella strains to antibiotics in Montenegro does not differ significantly from the sensitivity of Salmonella strains in Europe. Sensitivity of Salmonella isolates to all tested antimicrobial agents except to ceftriaxon was been slightly improved over testing period. Resistance rate to ceftriaxon was higher in 2010 than in 2005, and this fact deserves attention. Although the rate of sensitivity to individual antibiotics was higher in 2010 than in 2005, a slight increase of multi-resistant strains was marked in 2010 compared to 2005. Significantly increase susceptibility rate to nalidixic acid was observed between the two surveys. The surveillance of antimicrobial resistance in Salmonella spp. is very important. Also, it is important to maintain salmonella active surveillance of resistance on an international and intersectoral level.

\section{REFERENCES:}

1. Goburn B, Grassl GA, Finlay BB. Salmonella, the host and disease: A brief review. Immunol. Cell. Biol. 2007; (85): 112-118.

2. The Community Summary Report on Trends and Sources of Zoonoses, Zoonotic Agents, Antimicrobial Resistance and Foodborne Outbreaks in the European Union in 2006, The EFSA Journal (2007), 130.

3. Mohle-Boetani JC, Werner SB, Abbott S, et al. Salmonella Enteritidis infections from shell eggs: outbreaks in California. West J Med 1998; 169: 299-303.

4. Mermin J, Hoar B, Angulo FJ. Iguanas and Salmonella Marina infection in children: a reflection of the increasing incidence of reptile-associated salmonellosis in the United States. Pediatrics 1997; 99: 399-402. [PubMed] [CrossRef]

5. Su LH, Chiu CH, Chu C, Ou JT. Antimicrobial resistance in nontyphoid Salmonella serovars: a global challenge. Clin Infect Dis 2004 Aug 15;39(4):546-51. Epub
2004 Jul 30. [PubMed] [CrossRef]

6. Kasper DL, Fauci AS, Longo DL, Braunwald E, Hauser SL, Jameson JL Eds. Harrison's Principles of Internal Medicine. New York: The McGraw-Hill companies; 2005. p. 897-906.

7. Dhanashree B. Antibiotic susceptibility profile of Salmonella enterica serovars: Trend over three years showing reemergence of chloramphenicol sensitivity and rare serovars. Indian J Med Sci 2007 Oct;61(10):576-579. [PubMed] [CrossRef]

8. Coburn B, Grassl AG, Finlay BB. Salmonella, the host and disease: a brief review. Immunol Cell Biol. 2007 FebMar;85(2):112-118. Epub 2006 Dec 5. [PubMed] [CrossRef]

9. Pignato S, Giammanco G, Santagelo C, Giammanco G.M. Endemic presence of Salomonella bongori 48:z35:- causing enteritis in children in Sicily. Res. Microbiol. 1998 Jun;149(6):429-431. [PubMed] [CrossRef]

10. Bukitwetan P, Suryawidjaja JE,
Salim ChO, Hidayat A, Herwana E, Lesmana M. Serovar distribution and antibiotic susceptibility of nontyphoidal Salmonella isolated from pediatric patients in Jakarta, Indonesia. Southeast Asian J Trop Med Public Health. 2007 Nov;38(6):1088-1094. [PubMed]

11. Frost JA, Kelleher A, Rowe B. Increasing ciprofloxacin resistance in salmonellas in England and Wales, 19911994. J Antimicrob Chemother. 1996 Jan; 37(1):85-91. [PubMed] [CrossRef]

12. Herikstad H, Hayes P, Mokhtar M, Fracaro ML, Threlfall EJ, Angulo FJ. Emerging quinoloneresistant Salmonella in the United States. Emerg Infect Dis 1997 Jul-Sep;3(3):371-372. [PubMed]

13. Tauxe RV. Emerging foodborne diseases: an evolving public health challenge. Emerg Infect Dis 1997 Oct-Dec;3(4):42534. [PubMed]

14. WHO Fact Sheet Ne139, Revised April 2005.

\section{Corresponding autor:}

Assoc. Prof. Gordana Mijovic, M.D. Ph.D. Institute of Public Health, Podgorica Ljubljanska bb 81000 Podgorica, Montenegro tel. +382 20 412832; fax + 38220243728 e-mail: gordana.mijovic@ijzcg.me 